\title{
Patterns of rainfall and incidence of malaria in Purnia district (Bihar), India
}

\author{
Ranjana Kumari and B. N. Pandey \\ Eco-Genetical Research Laboratory P.G. Department of Zoology Purnea College \\ Purnia, Bihar (India) \\ E-mail b.n.pandey@hotmail.com
}

\section{ABSTRACT}

A study was carried out to find out co-relation between rainfall and instances of malaria infection in different villages of Purnia district. The study clearly indicates that there occurs a high positive co-relation between rainfall and instances of malaria in the studied villages of the district. There occurs a gradual increase in instances of malaria with gradual rise in rainfalls. The study also indicates that besides rainfall, ambient temperature also plays a key role in the incidence of malaria as in certain months the incidence of malaria was not found having but rainfall. Maximum incidence of malaria was noticed during rainy season followed by summer and winter seasons.

\section{INTRODUCTION}

Rainfall plays an important role in malaria as it increases relative humidity and thereby the longevity of the adult mosquitoes, besides providing water as the medium for aquatic stages of the mosquitoes (McMichael and Martens, 1995). No doubt, rainfall provides breeding ground of the mosquitoes, if it is moderate while it destroys breeding sites and flush out larvae, when it is in excess. Rainfall provides breeding sites for mosquitoes to lay their eggs, and ensures a suitable relative humidity of at least 50 to $60 \%$ to prolong mosquito survival (Reiter, 2001). Many workers have reported a positive correlation between rainfall and the incidence of Plasmodium falciparum (Gupta, 1996 and Bouma et al.; 1996).

Among vector born diseases, malaria is known to be influence by special and temporal changes in the ambient environment, and caused by climatic factor through distribution of carrier vector and pathogens. Malaria is one of the oldest and major health problem of the world. It has now been identified as the disease most likely affected by climatic changes (WHO; WMO; UNEP, 1996). Climate variability and breeding activity of anopheles are concerned one of the important environmental contributors of malaria transmission (Pemola and Jauhari; 2006). There is dearth of literature on climatic variable and malaria transmission from India. A few studies has reported the role of factors like urbanization, irrigation, location of houses, habits of sleeping outside, rearing of animals as well as drainage system on the malaria incidence. (Batra et al. 2001, Joshi et al. 2005, Saini et al. 2009 and Pandey et al. 2011). Keeping this aim in mind, the present work was under taken to explore the extent of relationship of rainfall with instances of malaria in rural areas of Purnia district.

\section{MATERIALS AND METHODS}

\section{Study areas:}

The present study was carried out in different villages of Purnia district. Purnia is one of the oldest district of Bihar which live at $25^{0}-24^{0}$ and $26^{0}-7^{0}$ north latitude and $86^{0}-39^{0}$ and $88^{0}-3^{0}$ west longitude. The district is located at height of 315 meters from 
the sea level. The district is reach in flora and fauna. It is popularly known as Poor's man Drajeeling . As per Indian census report of 2011, the population of Purnia is about 3273127 (M -1695815, F - 1577298 ).

\section{Meterological data:}

Daily rainfall (mm) was recorded and pooled for all the months from June 2010 to May 2011.

\section{Epidemiological data:}

Epidemiological surway was conducted to collect the information regarding malaria infected persons in purnia district, from private pathology centar ,hospitals ,and PHC of purnia district . Door to door surway was also made to record the instances of malaria infection in study area.

\section{RESULT AND DISCUSSION}

Data of monthly rainfall (mm) and instances of malaria in purnia district are shown in table 1 and fig. 1 . The result of the study show that except for colder months of the year (Nov to Feb), infection of malaria was in rise during rest of the eight months .The study revealed a trained of rise from the month of May to August (Table -1 and Fig -1), When peak value of patients were found in the district. The instance of malaria started falling from September (Table 1 and Fig. 1).The instances of malaria increases as the amount of rainfall increased.

Table 1: Average monthly value of rainfall and malaria cases in Purnia district during the period of Sept. 2010 to Aug. 2010.

\begin{tabular}{|l|c|c|}
\hline \multicolumn{1}{|c|}{ MONTHS } & RAINFALL in mm & NO. OF POSITIVE CASES \\
\hline SEP. 2010 & 7.38 & 9 \\
\hline OCT.2010 & 5.65 & 7 \\
\hline NOV.2010 & 0.2 & 0 \\
\hline DEC.2010 & Trace & 0 \\
\hline JAN 2011 & 0.15 & 0 \\
\hline FEB 2011 & 2.86 & 1 \\
\hline MARCH2011 & 2.9 & 2 \\
\hline APR2011 & 0.82 & 0 \\
\hline MAY2011 & 4.33 & 5 \\
\hline JUNE 2011 & 13.89 & 10 \\
\hline JULY 2011 & 11.28 & 9 \\
\hline AUG 2011 & 14.51 & 12 \\
\hline
\end{tabular}

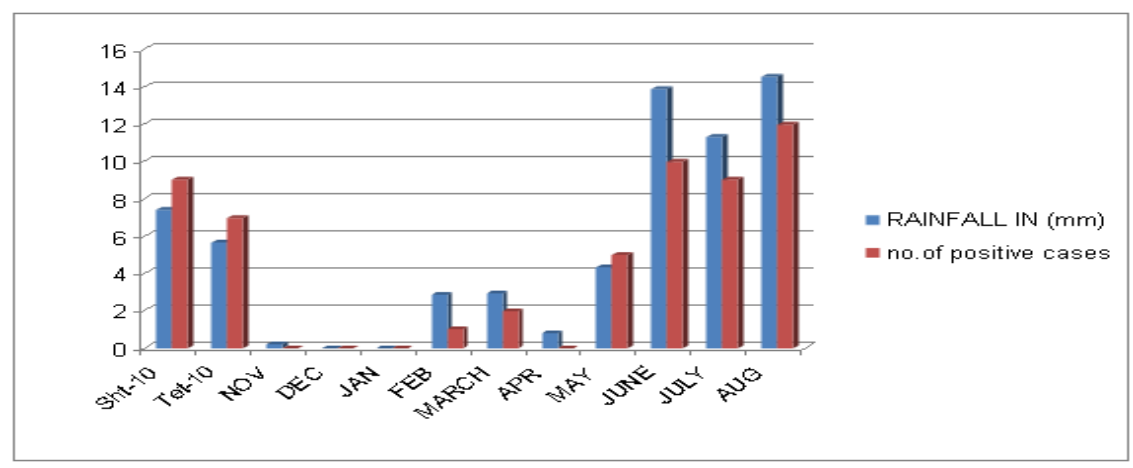

Fig. 1: Average monthly value of rainfall and malaria cases in Purnia district during the period of September 2010 to August 2010. 
The maximum cases of malaria where observed in rainy season, when rainfall by maximum (Table -1) followed by summer and winter. The incidence of malaria was maximum in the month of August followed by June and July. This clearly indicate that there is positive co-relation between incidence of malaria and pattern of rainfall. Such type of co-relation has been found by many workers such as Pemola and Jauhari; 2006, Battacharya et al. 2006, Rama samy et al., 1992, Singh and Sharma 2002 and Sain et al. 2009.

The malaria shows its appearance in the month of February, when ambinent temperature is quite congenial for the parasite, vector as well as host.

\section{CONCLUSION}

On the basis of present study, it can be concluded that there is a positive co-relation between patterns of rainfall and instances of malaria. The instances of malaria show an increase from the month of May attaining its peak in the month of August with increase in the amount of rainfall. Maximum number of malaria patients were found in rainy season followed by summer and winter season. The present study also reveals that besides rainfall, ambient temperature also plays a key role in the instances of malaria.

\section{REFERENCES}

Batra, C. P. Adak, T. Sharma, V. P. and Mittal, P.K. (2001). Impact of urbanization on bionomics of A. culicifacies and A. stephensi in Delhi. Indian J. Malariol.

Bhattacharya, S. Sharma, C. Dhiman, R. C. and Mitra, A.P (2006). Climate Change and malaria in India.

Gill, C. A (1921). The role of meterology in malaria. Indian J. Med. Res.

Joshi, V. Sharma, R.C.; Singhi, M. Singh, H. Sharma, K. Sharma, Y. and Adha S. (2005). Entomological studies on malaria in irrigated and non-irrigated areas of Thar desert, Rajasthan, Indian. J. Vect. Borne.

Pemola, N. and Jauhari, R. K. (2006). Climatic variables and malaria Incidence in Dehradun , Uttaranchal, India.

Rama samy, R. Ramasamy, M. S. Wijesundera, D. A. Wijesundera, A. P. Dewit, I and Ranasinghe, C. (1992). High seasonal malaria transmission rates in the intermediate rainfall Zone of srilanka.

Sharma, R. S. Sharma, G. K and Dhillon, G. P. S (1996). In Epidemiology a malaria in India. (Eds Sharma, R. S. Sharma, G. K. and Dillon, G. P. S) Government of India ministry of Health and Family welfare.

Singh, R. P. Singh, S. Jauhari, R. K. (1994). Incrimination of anopheles stephensi liston 1901 as a vector of malaria in South-eastern Doon Vally.

Bouna, M. J; Dya C.; Van der Ky, H.J. (1996) Falciparum malaria and climate changes in the Northwest Frontier Province of Pakistan. Am. J. Trop. Med. Hyg; 55(2): 131-7.

Gupta, R. (1996). Correlatin of rainfall with upsurge of malaria in Rajasthan. J. Assoc. Phys. Ind., 44:385-9.

Mc. Michael. A. J. and Martens, W. J. M. (1995). The health impact of global climate changes: grasping with scenario predictive models and multiple uncertainties. Ecosyst. Hlth., 1:23-33.

Pampana, E. (1969). Ed. A text Book of Malaria Eradication. Oxford university press. London (U.K). 